\title{
HOMEOSTASIS AND POLYMORPHISM IN VERNAL DEVELOPMENT OF CHAOBORUS AMERICANUS ${ }^{1}$
}

\author{
WILliam E. BRADSHaW ${ }^{2}$ \\ Department of Zoology, University of Michigan, Ann Arbor, MI 48104 and \\ Biological Laboratories, Harvard University, Cambridge, $M A 02138$
}

\begin{abstract}
Last instar larvae of Chaoborus americanus overwinter in a state of developmental arrest (diapause) but remain otherwise active and capable of feeding. The diapausing larvae are developmentally responsive to long-day photoperiod and food. A portion of a wild-caught population responds rapidly to these conditions; the remainder of the population is more conservative. For either morph, the closer an individual approaches adult emergence, the more its rate of development is retarded by a small drop in water temperature. This response to temperature both promotes synchronous adult emergence and insures favorable climatic conditions at that time. Even this individual thermal homeostasis does not ensure survivorship throughout the total range of vernal climates encountered in a single shallow pond. The fast-responding morph predominates following warm, continuous springs; the more conservative morph predominates following a spring where the initial thaw is succeeded by a refreezing of the pond. Response time polymorphism is thus envisioned as an adaptive extension of the individual thermal homeostasis and serves as a model for persistent polymorphism.
\end{abstract}

\section{INTRODUCTION}

How animals respond to environmental perturbation depends upon the absolute magnitude of the perturbation, the rate at which it is imposed, and its predictability. If the perturbation $(P)$ is small, its rate of imposition $(\mathrm{d} P / \mathrm{d} t)$ over time $(t)$ will be of little consequence. Animals will ordinarily cope by accommodation. A large perturbation and small rate of imposition will evoke some sort of acclimation. If, however, the perturbation is too large for accommodation and $\mathrm{d} P / \mathrm{d} t$ too rapid for acclimation, individual homeostasis will not suffice and greater fitness will accrue to individuals that are in some way pre-adapted or pre-acclimated. In the present study, I propose that large perturbation and rapid $\mathrm{d} P / \mathrm{d} t$ imposed in an unpredictable manner will result in a polymorphism of pre-adapted phenotypes and when imposed in a predictable manner will result in individual pre-acclimation.

Winter is a regular occurrence that for many organisms constitutes an extreme perturbation. The larvae of the non-biting mosquito Chaoborus americanus respond to short daylength and enter a dormant state (diapause) during which development but not activity ceases (Bradshaw 1972). In this state, they retreat to a constant-temperature zone beneath the ice of shallow Nearctic ponds. After several months, the larvae rely upon two major cues to re-initiate development: food and long days (Bradshaw 1969, 1970). Vernal climate in temperate latitudes is not, however, consistent from one year to another but ranges from an early, continuously warm spring

\footnotetext{
${ }^{1}$ Received July 24, 1972; accepted December 30, 1972

2 Present address: Department of Biology, University of Oregon, Eugene, OR 97403
}

through alternating warm-cool-warm springs to an extreme thaw-freeze-thaw spring. The onset of winter is reliably predictable on the basis of daylength; $C$. americanus pre-acclimate by entering diapause. Vernal climate is unpredictable, and climatic fluctuations can produce perturbations that exceed the homeostatic capacity of developing individuals. Chaoborus americanus have adapted to this vernal uncertainty by being polymorphic for response time to trophic and photoperiodic cues.

The overwintering larvae consist of two varieties: a larger, yellower morph and a smaller, paler morph. Preliminary investigations (Bradshaw 1967) suggested that the large yellow larvae tended to terminate diapause more rapidly in response to long days with food than did the small pale larvae. Response time is most easily quantified by observing the number of long days with food required for half the larvae to molt to pupae. While readily observed in the laboratory, this parameter is a composite of diapause termination per se and post-diapause morphogenesis leading to pupation. The time required for diapause termination and post-diapause morphogenesis may be determined by long-day, short-day pulse, chase experiments as described earlier (Bradshaw and Lounibos 1972). In the present paper, I shall consider all these components of development, how temperature affects them, and how they relate to vernal development in $C$. americanus.

\section{Materials AND Methods}

I obtained overwintering larvae from either the Southwest Woods Pond or George Pond on the University of Michigan's E. S. George Reserve, near Pinckney, Michigan $\left(42^{\circ} 30^{\prime} \mathrm{N}, 84^{\circ} 00^{\prime} \mathrm{W}\right)$. They were 
transferred on the day of capture to a holding incubator where they were provided a short-day (light: dark $=8: 16$ ) photoperiod at $5^{\circ} \mathrm{C}$ without food until needed for experimentation. Short-day experimental animals received $8(1966-1967)$ or 12 (1968-1970) hours of light per day and long-day experimental animals 16 (1968-1969) or 17 (1966-1967, 1970) hours of light per day. Food consisted of an excess of mosquito larvae, Culex pipiens (1966-1969), or an excess of freshly hatched, washed brine shrimp, Artemia salina (1970).

For reasons described previously (Bradshaw 1969), I used the appearance of pupae to score development and have adopted the following abbreviations:

$$
\begin{aligned}
& P_{50}= \text { the number of days for } 50 \% \text { of the surviving } \\
& \text { population to pupate } \\
&=\text { the number of days when } \\
& \frac{\text { number of pupated individuals }}{\left(\begin{array}{c}
\text { initial } \\
\text { sample size }
\end{array}\right)-\left(\begin{array}{c}
\text { number of larvae } \\
\text { having died }
\end{array}\right)}=.50 \\
& T_{50}=\text { the number of long days with food required } \\
& \text { for } 50 \% \text { termination of diapause } \\
&=\text { the regression equation, }
\end{aligned}
$$

$$
\% \text { pupation }=a+b\left(\begin{array}{c}
\text { number of days exposure } \\
\text { to long days with food } \\
\text { before continuous short } \\
\text { days without food }
\end{array}\right)
$$

solved for $50 \%$ pupation

$\mathrm{PDM}=$ post-diapause morphogenesis

$$
=P_{50}-T_{50}
$$

$\mathrm{DAP}=$ the number of days spent as a pupa

For all experiments, wild populations were removed from the holding incubator and warmed to room temperature. A portion of these animals was set aside for control purposes and designated wild mix (WM). From the remainder, two experimental populations were formed, the first consisting of subjectively selected large yellow individuals (LY), the second consisting of subjectively selected small pale individuals (SP). The largest individuals are not invariably the yellowest and there is a continuum from the largest, yellowest to the smallest, palest. Intermediate-sized and pigmented forms could not easily be designated as either large yellow or small pale larvae and were ordinarily discarded.

In experiments involving different temperatures, I calculated $Q_{10}$ 's as follows:

$$
\begin{aligned}
\log Q_{10}= & 10 /\left(T_{2}-T_{1}\right) \times \\
& \log \left[\left(\text { rate at } T_{2}\right) /\left(\text { rate at } T_{1}\right)\right]
\end{aligned}
$$

where $T_{2}$ is the higher of two temperatures and $T_{1}$ is the lower.

To model the relationship between the duration of

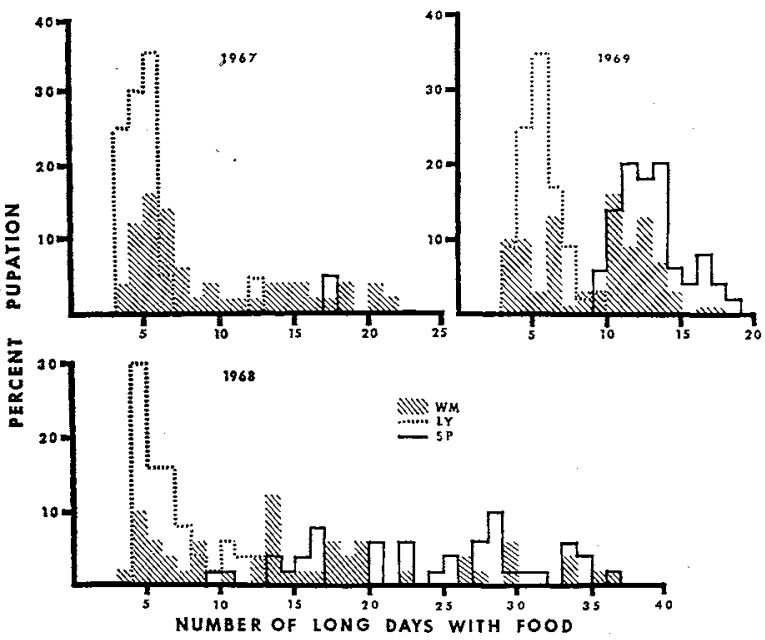

FIG. 1. Distribution in response of wild mix (WM), large yellow (LY), and small pale (SP) larvae to long days with food at $25^{\circ} \mathrm{C}$ : comparison between years. Dates of capture and initiation of the experiments are given in Table 1, except that for 1969 the larvae were caught February 24, and the experiment started April 6 .

a given stage of development, $D$, and temperature, $T$, I considered three formulations:

$$
D=\frac{a}{T-b}
$$

where $a$ is the number of day-degrees required for the completion of a developmental stage and $b$ is the minimum temperature at which development can proceed;

$$
\log D=\log a+\frac{25-T}{10} \log b
$$

where $a$ is the duration of the developmental stage at $25^{\circ} \mathrm{C}$ and $b$ is the $Q_{10}$;

$$
\log D=a-b \log T
$$

where $a$ and $b$ are constants.

\section{EXPERIMENTAL RESULTS}

\section{Effects of long days with food}

To determine possible differences in rates of developmental response, I exposed wild mix, large yellow, and small pale larvae from George Pond to continuous long days with food at $25^{\circ} \mathrm{C}$. Dates caught, dates experiments initiated, and sample sizes are given in Table 1. The duration of the experiments varied, but for each starting date, the three types of larvae were all observed for equal lengths of time and in no case for less than 20 days.

As may be seen in Figure 1, the large yellow larvae pupated soon after imposition of long days with food. The small pale larvae were much slower in their response. When the distribution of pupation in time 
TABLE 1. Comparison of the developmental responses of the wild mix (WM), large yellow (LY), and small pale (SP) larvae from George Pond when exposed to long days with food at $25^{\circ} \mathrm{C}^{\mathrm{a}}$

\begin{tabular}{|c|c|c|c|c|c|c|}
\hline$n$ & $\mathrm{Ct}$ & St & Type & $\% \mathbf{P}$ & $P_{50}$ & $\% \mathrm{M}$ \\
\hline 50 & 12-II-67 & 4-III-67 & WM & 100 & 7.7 & $61 \#$ \\
\hline 20 & $12-$ III-67 & 26-III-67 & LY & 100 & 4.8 & $23 \#$ \\
\hline 20 & $12-I I-67$ & 26-III-67 & SP & 5 & - & - \\
\hline 50 & $25-\mathrm{II}-68$ & 6-IV-68 & WM & 98 & 14.5 & 57 \\
\hline 50 & $25-I I-68$ & $6-I V-68$ & LY & 94 & 6.2 & 58 \\
\hline 50 & $25-I I-68$ & $6-\mathrm{IV}-68$ & SP & 80 & 27.5 & 78 \\
\hline $50 * *$ & $13-I I-69$ & 5-III-69 & WM & $83 \pm 8$ & $11.1 \pm 2.4$ & $58 \pm 8$ \\
\hline $50 * *$ & $13-$ II-69 & 5-III-69 & LY & $96 \pm 2$ & $7.0 \mp 0.0$ & $24 \pm 4$ \\
\hline $50 * *$ & $13-\Pi 1-69$ & 5-III-69 & SP & $77 \pm 10$ & $21.3 \pm 1.9$ & $64 \pm 5$ \\
\hline $50 *$ & 24-II-69 & $5-I V-69$ & WM & $69 \pm 3$ & $10.5 \pm 1.0$ & $56 \pm 3$ \\
\hline $50 *$ & $24-I I-69$ & 5-IV-69 & LY & $65 \pm 1$ & $4.6 \pm 0.4$ & $37 \pm 14$ \\
\hline $50 *$ & 24-II-69 & 5-IV-69 & $\mathrm{SP}$ & $51 \pm 3$ & $13.8 \pm 0.7$ & $85 \pm 7$ \\
\hline
\end{tabular}

a $n$, sample size; $\mathrm{Ct}$, date caught; $\mathrm{St}$, date experiment started; \% $\mathrm{P}$, percent pupation; $P_{50}$, as defined in text; $\% \mathrm{M}$, percentage males determined by examining the pupae except \#, by examining the adults. *, duplicate or **, triplicate of $n$ animals each. Plus or minus standard deviation when experiments were replicated.

was distinctly biomodal as in 1969 (Fig. 1, 2A), the distribution of pupation of the large yellow corresponded to the earlier mode, the small pale to the later mode. When the second peak in pupation of the wild mix larvae had a low mode and a broad distribution, the peak in pupation of the small pale larvae tended to be broad as well (Fig. 1, 1968); when the second peak in pupation of the wild mix larvae had a high mode and narrow distribution, the peak in pupation of the small pale tended to be narrow as well (Fig. 1, 1969). Samples of the large yellow larvae tended to have a higher proportion of females than the wild mix populations; samples of the small pale larvae tended to have a higher proportion of males than the wild mix population, even though males predominate in the latter (Table 1).

\section{Gradient experiments}

Selection of large yellow and small pale larvae from a wild mix population was sometimes difficult because many of them were intermediate in size and pigmentation. Consequently, these were discarded and the sum reactions of the large yellow and small pale larvae is not the reaction of an intact wild mix population. In order to understand the contribution of the large yellow, intermediate, and small pale larvae to the developmental response of an intact wild mix population, I undertook the following experiments.

I selected a gradient from large yellow to small pale from a large stock caught in George Pond April 4, 1969. On April 5, 1969, I stirred the stock vigorously and took a sample of 1,280 larvae from it. I sorted the entire sample by taking the 100 largest yellow individuals and placing them in one jar, taking the next 100 largest yellow and placing them in a second jar; I repeated this procedure through the 1,280 animals present and thus established a gradient from large yellow to small pale in a wild mix population in twelve 100-animal steps and one 80-animal step (the smallest and palest). I then placed the graduated population on long days with food at $25^{\circ} \mathrm{C}$ and observed them until $99 \%$ of all 1,280 larvae had either developed or died.

The wild mix animals graduated from large yellow to small pale exhibited $87 \%$ pupation in 45 days. During this time, $12 \%$ of the larvae had died and $1 \%$ remained alive as larvae. The $P_{50}$ 's were 11.5 days for the entire wild mix, 5.1 days for the 400 largest yellow, and 19.4 days for the 380 smallest pale. For any step in the gradient, the $P_{50}$ for males was less than that for the corresponding females and the higher $P_{50}$ 's were found at the small pale end of the gradient (Fig. 2B). The distributions of males and females were bimodal, with the peaks for males staggered to the small pale end of the gradient (Fig. 2C-D).

\section{Distribution of developmental response to sub-maximal stimuli}

Earlier studies (Bradshaw 1969) revealed that about half of an overwintering population would develop in response to long days alone (long days without food) during January-April. After larvae have been chilled several months in the laboratory, the response to long days alone diminishes but that to food alone (short days with food) increases. Preliminary experiments suggested that portions of the population overwintering 1969-1970 would respond to long days alone, food alone, or even simple warming (short days without food). The following experiments are meant to illustrate the distribution of response to these partial stimuli among the wild mix of larvae caught February 23, 1970.

On March 4, 1970, I exposed samples graduated from large yellow to small pale to long days with food (10 steps of 50 larvae each), to long days without food (10 steps of 50 larvae each), to short days with food (10 steps of 50 larvae each), and to short days without food (5 steps of 20 larvae 


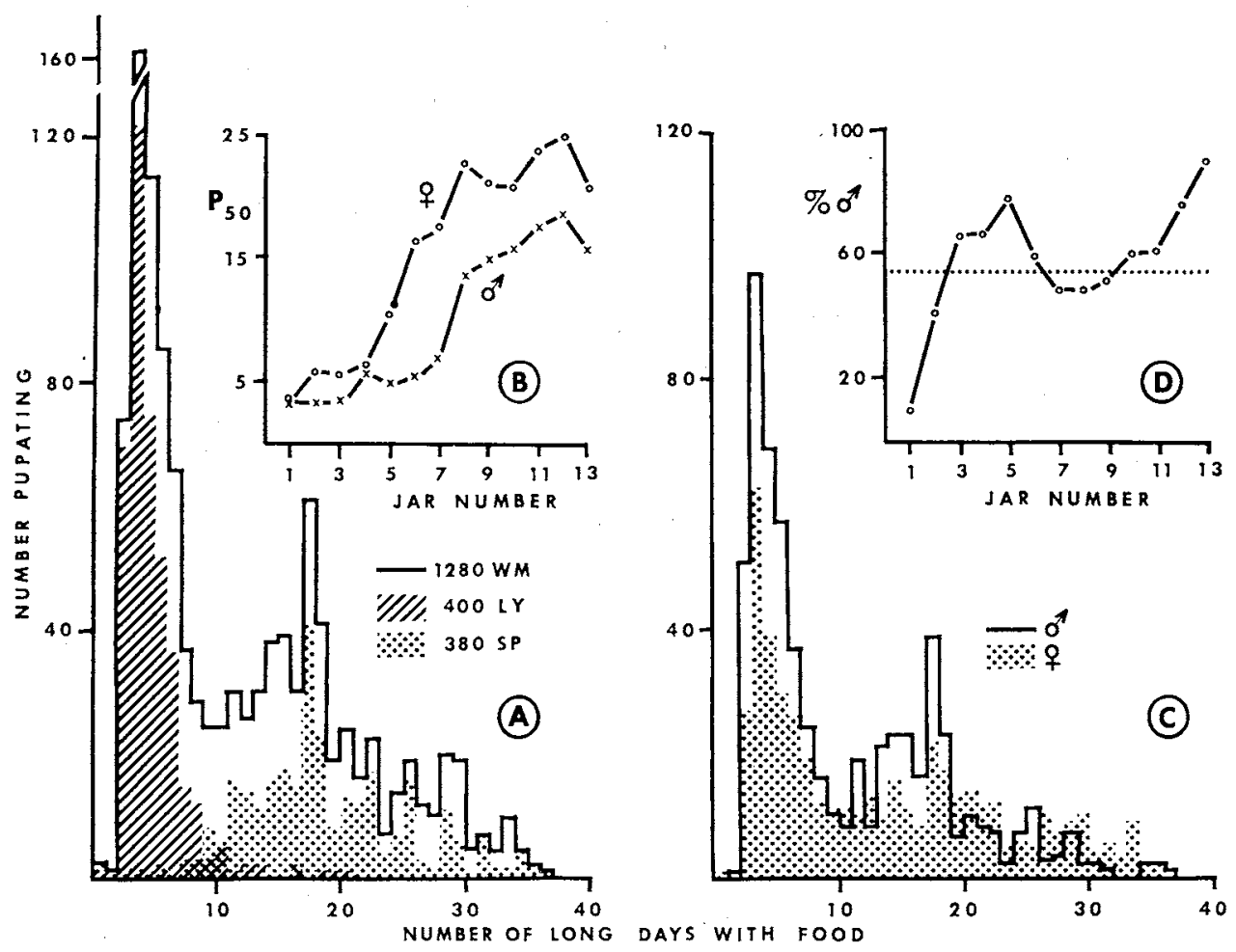

FIG. 2. Development of a graduated wild mix population in response to long days with food at $25^{\circ} \mathrm{C}$. WM, wild mix; LY, large yellow; SP, small pale. The largest yellow are in jar number 1 , the smallest pale in jar 13. (A) Distribution of response by 1,280 wild mix, the 400 largest yellow, and the 380 smallest pale larvae. (B) $P_{50}$ for males and females as a function of position in the gradient. (C) Distribution of response by males and females among the 1,280 wild mix larvae. (D) Percentage of males in each step of the gradient. The dotted line indicates $57 \%$, the percentage of males in the total wild mix sample.

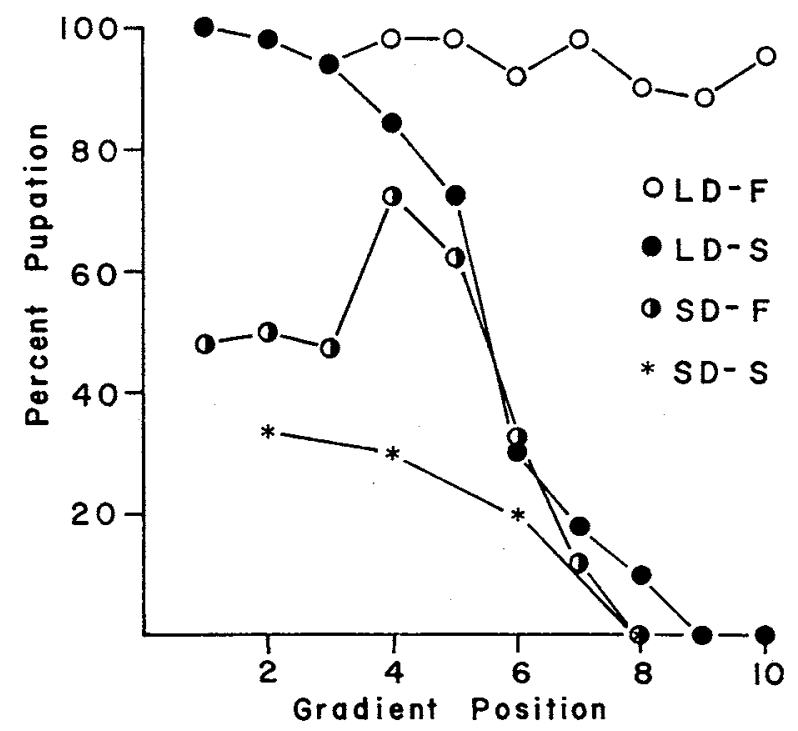

Fig. 3. Distribution of development in response to long days with food (LD-F), long days without food (LD-S), short days with food (SD-F), and short days without food (SD-S). Only 5 steps in the gradient were exposed to short days without food but the scale has been expanded for purposes of comparison. each). As shown in Figure 3, 25 long days with food elicited $88 \%-100 \%$ development at each gradient position. Response to long days alone, food alone, or warming was generally restricted to the large yellow larvae (Gradient Positions 1-6); their response was greatest to long days alone, less to food alone, and least to warming.

\section{Variation in response to sub-maximal stimuli}

The comparative responses of large yellow larvae between and within years to long days with food, long days without food, and short days with food are shown in Table 2. Percent pupation in response to long days without food and short days with food were positively correlated to each other and negatively correlated with $P_{50}$ (Spearman's rank correlation: $r_{\mathrm{s}}$ significant at the $95 \%$ level of confidence for all comparisons). The response to food alone was significantly less than to long days alone ( $t$ test for paired comparisons: $t=3.5 ; \mathrm{P}<0.05$ ).

\section{Developmental basis of variation}

Variation in response to photoperiodic and trophic cues could result from a variety of developmental 
TABLE 2. Developmental response of large yellow larvae to long days with food (LD-F), long days without food (LD-S), and short days with food (SD-F) ${ }^{\mathrm{a}}$

\begin{tabular}{rcccc}
\hline Caught & Started & $\begin{array}{c}P_{50}: \\
\text { LD-F }\end{array}$ & $\begin{array}{c}\% \mathrm{P}: \\
\text { LD-S }\end{array}$ & $\begin{array}{c}\% \mathrm{P}: \\
\text { SD-F }\end{array}$ \\
\hline $3-19-67$ & $3-26-67$ & 4.8 & 33 & - \\
$1-08-68$ & $2-02-68$ & 8.5 & 2 & 0 \\
$2-25-68$ & $4-06-68$ & 6.2 & 14 & 0 \\
$1-08-69$ & $2-02-69$ & 7.2 & 12 & 0 \\
$1-08-70$ & $2-08-70$ & 4.0 & 84 & 30 \\
$2-23-70$ & $3-04-70$ & 3.7 & 90 & 66 \\
$11-14-70$ & $1-02-71$ & 5.6 & 86 & 30 \\
\hline
\end{tabular}

a Caught, date caught from George Pond; Started, date experiment was initiated. $P_{50}$ as defined in the text; $\% \mathbf{P}$, percent pupation.

differences. The small pale morph could consist of third instar larvae, the large yellow morph of fourth instar larvae. Alternatively, both morphs might be in the same instar but the small pale merely early and the large yellow late fourth instar larvae. If they are both at the same age in the same instar, the polymorphism could result from a difference in the time required for the termination of diapause or the completion of post-diapause morphogenesis. The following experiments utilize larvae captured from George Pond February 23, 1970, and are designed to resolve these alternatives.

(1) Developmental stages of overwintering larvae. - To find the developmental stage of overwintering C. americanus, I used a dissecting microscope and ocular micrometer to measure total length, head capsule length, and length of the longest mandibular tooth. These measurements are meant to illustrate the range in dimensions of soft parts, hard parts, and the trophic apparatus, respectively. I measured only a few of the largest, yellowest and a few of the smallest, palest larvae and compared my range of measurements with those given by Cook (1956) for fourth instar larvae of Nearctic C. americanus.
The total body length of larvae caught in George Pond on February 23, 1970, ranged from 9.0 to $15.0 \mathrm{~mm}$, compared to Cook's range of 10.0 to 13.0 $\mathrm{mm}$; the head capsule ranged from 1.06 to $1.20 \mathrm{~mm}$ compared to Cook's values of 1.00 to 1.30 . The longest mandibular tooth varied only from 0.15 to $0.17 \mathrm{~mm}$ from the smallest, palest to the largest, yellowest larva. Cook did not make this latter meam surement.

These results suggest that all overwintering larvae are in the fourth instar. To confirm this supposition, I placed 10 small pale larvae into individual jars and exposed them to long days with food. I examined the jars daily for exuviae, indicating a molt from one larval instar to another. The larvae pupated after 20-31 days $\left(P_{50}=27.0\right)$. One and only one fresh exuvia was observed in each vial and that one on the day the pupa was first observed. To allow for the unlikely possibility that $C$. americanus or $A$. salina eat shed exuviae, I transferred a single fresh exuvia to each of three jars containing a small pale larvae being fed $A$. salina. The host larvae pupated 4,5 , and 8 days thereafter. In each case two and only two exuviae were observed in the jar on the day the host larva pupated. The shed larval exuvia is therefore not eaten by either the small pale larvae or the shrimp; nor does it decompose within 4-8 days. These results show that the small pale larvae do not undergo a larval molt prior to the pupal molt.

(2) Growth of small pale into large yellow larvae. - The following experiments are intended to determine whether small pale larvae, allowed to feed for a long time on short-day photoperiod, will grow or transform into large yellow larvae. For these experiments I used the larvae that had not developed in response to short days with food from the experiments in Fig. 3 above. Gradient positions 1-6 were pooled to form samples of large yellow larvae, 7-10 to form samples of small pale larvae.

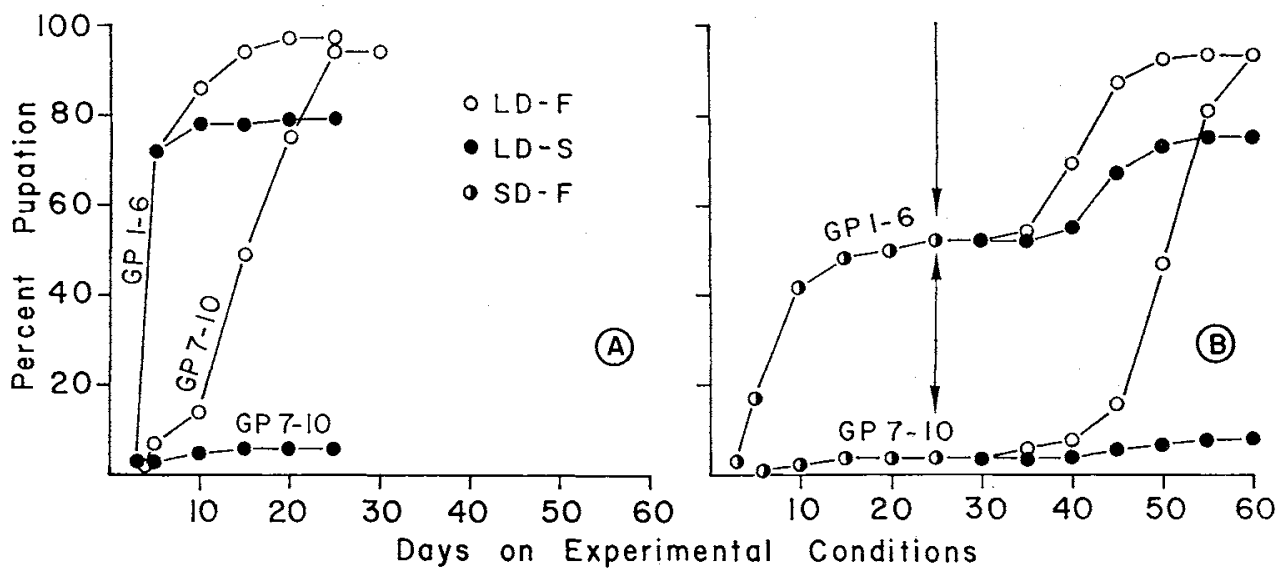

FIG. 4. Development in response to long days with and without food (A) without any prior treatment and (B) after 25 short days with food. Abbreviations as in Fig. 3. 
Cumulative percent development in response to long days with and without food is shown in Fig. 4A. The response of larvae to long days with food in GP (Gradient Positions) 7-10 was delayed as compared to those in GP 1-6. $P_{50}$ for the former group was 15.2 days and for the latter was 4.2 days. Long days alone elicited rapid development in GP 1-6 and negligible development in GP 7-10. These results serve as a basis of comparison for the experiments below.

Twenty-five short days with food evoked $52 \%$ and $4 \%$ pupation among the larvae in GP 1-6 and $7-10$, respectively (Fig. 4B). In each group, the larvae remaining after 25 short days with food were divided equally; half were exposed to long days with food, half to long days without food. Long days with food promoted substantial development in both groups, but only 16.5 long days with food were required for half the larvae in GP 1-6 to pupate compared with 25.0 days for those in GP 7-10. Long days without food evoked substantial development only among larvae in GP 1-6 (Fig. 4B). In the latter group, 23.0 long days without food were required for half the larvae to pupate. These results show that 25 short days with food do not enable small pale larvae to respond as rapidly to long days with food as large yellow larvae; nor does this period of feeding enable small pale larvae to respond to long days alone.

(3) Termination of diapause and post-diapause morphogenesis.-To determine the $T_{50}$ of large yellow and small pale larvae, I sorted 12 samples of 100 wild mix larvae each from large yellow to small pale in 5 steps of 20 larvae. I then exposed separate graduated samples to $0,1,2,3,4,6,9,12,15,18$, 21 , or 25 long days with food followed by short days without food for a total experimental time of 25 days. Fifteen or more long days with food elicited $90 \%$ or more pupation in all gradient positions; I therefore used the pooled cumulative percent pupation of these gradients to find $P_{50}$. To compensate for the development in response to short days with food during 1970 (Fig. 3), percent development was corrected as follows:

corrected percent development for $T_{50}=$

$$
(\mathrm{PL}-\mathrm{TS}) /(\mathrm{TL}-\mathrm{TS})
$$

corrected percent development for $P_{50}=$

$$
(\mathrm{CL}-\mathrm{CS}) /(\mathrm{TL}-\mathrm{CS})
$$

where $\mathrm{PL}=$ total percent response to pulsed long days with food after 25 days

$\mathrm{TS}=$ total percent response to short days without food after 25 days

$\mathrm{TL}=$ total percent response to continuous long days with food after 25 days
TABLE 3. $P_{50}, T_{50}$, and PDM among large yellow (GP 2 and 4) and small pale (GP 8 and 10) larvae

\begin{tabular}{llrc}
\hline \hline & $P_{50}$ & $T_{50}$ & PDM \\
\hline GP 2 & 4.0 & 0.7 & 3.3 \\
GP 4 & 3.8 & 0.5 & 3.3 \\
GP 6 & 3.9 & $\overline{7.0}$ & $\overline{7.8}$ \\
GP 8 & 14.8 & 10.0 & 5.4 \\
GP 10 & 15.4 & & \\
\hline
\end{tabular}

$$
\begin{aligned}
\mathrm{CL}= & \text { cumulative percent response to long } \\
& \text { days with food } \\
\mathrm{CS}= & \begin{array}{l}
\text { cumulative percent response to short } \\
\text { days without food }
\end{array}
\end{aligned}
$$

As seen in Table 3, both $T_{50}$ and PDM increased with gradient position. At GP 6, a great deal of variation occurred in the response to pulsed long days with food; consequently, it was not possible to calculate a meaningful $T_{50}$ or PDM for this gradient position. The increase in $T_{50}$ is both absolutely and proportionally greater than the increase in PDM. Developmental differences between the large yellow and small pale larvae are therefore due mainly to the time required for the termination of diapause and, to a lesser extent, to the completion of post-diapause morphogenesis.

\section{Effects of temperature}

Thus far, I have considered comparative developmental times only at $25^{\circ} \mathrm{C}$. To investigate the effect of lower temperature on developmental time, I compared $P_{50}$ 's and DAP's for wild mix, large yellow, and small pale larvae observed at $25^{\circ} \mathrm{C}$ with those observed at $15^{\circ} \mathrm{C}$.

I subjected two groups of 50 wild mix, 50 large yellow, and 50 small pale larvae from the Southwest Woods Pond to long days with food and observed

TABLE 4. Thermal dependency of $P_{50}$ and DAP among wild mix (WM), large yellow (LY), and small pale

\begin{tabular}{|c|c|c|c|c|c|}
\hline${ }^{\circ} \mathrm{C}$ & Type & $P_{50}$ & DAP & $Q_{10} P_{\text {ธ } 0}$ & $\overline{\mathrm{Q}_{10} \mathrm{DAP}}$ \\
\hline 25 & WM & $11.8(50)^{\mathrm{a}}$ & $2.2(43)$ & \multirow{2}{*}{2.1} & \multirow{2}{*}{4.5} \\
\hline $\begin{array}{l}15 \\
25\end{array}$ & $\begin{array}{l}\text { WM } \\
\text { LY }\end{array}$ & $\begin{array}{r}25.0(50) \\
7.8(50)\end{array}$ & $\begin{array}{l}9.8(25) \\
2.1(43)\end{array}$ & & \\
\hline $\begin{array}{l}15 \\
25\end{array}$ & $\begin{array}{l}\text { LY } \\
\text { SP }\end{array}$ & $\begin{array}{l}17.4(50) \\
18.6(50)\end{array}$ & $\begin{array}{l}9.7(33) \\
2.0(24)\end{array}$ & 2.2 & 4.6 \\
\hline $\begin{array}{l}15 \\
25\end{array}$ & $\begin{array}{l}\text { SP } \\
\text { SP* }\end{array}$ & $\begin{array}{l}31.0(50) \\
18.0(50)\end{array}$ & $\begin{array}{l}9.3(15) \\
2.1(21)\end{array}$ & 1.7 & 4.7 \\
\hline 15 & SP\# & $52.0(100)$ & $10.2(46)$ & 2.9 & 4.6 \\
\hline
\end{tabular}
(SP) larvae caught in the Southwest Woods Pond 8-I-69 and started on experimental conditions 2-II-69, except *, caught in George Pond 8-I-69 and started 2-II-69 and \#, caught in George Pond 13-II-69 and started 25-ПI-69 
TABLE 5. Temperature dependency of diapause termination, post-diapause morphogenesis, and the duration of the pupal instar of large yellow larvae caught from George Pond February 24, 1969, and exposed to experimental conditions starting April 7, $1969^{2}$

\begin{tabular}{ccccc}
\hline${ }^{\circ} \mathrm{C}$ & $T_{50}$ & $P_{50}$ & PDM & DAP \\
\hline 25 & $3.4 \pm 0.6(15)$ & $6.2 \pm 0.1(3)$ & $2.8 \pm 0.6$ & $2.2 \pm 0.4(33)$ \\
20 & $4.3 \pm 0.9(15)$ & $9.6 \pm 1.2(3)$ & $5.2 \pm 1.4$ & $3.9 \pm 0.4(58)$ \\
15 & $6.0 \pm 0.9(15)$ & $15.2 \pm 1.4(3)$ & $9.3 \pm 1.7$ & $8.6 \pm 0.7(61)$ \\
\hline
\end{tabular}

${ }^{a}$ Plus or minus standard deviation is given where appropriate. ( ), sample size; for $T_{50}$ and $P_{50}$, the number of 50 larvae samples; for DAP, the number of individual larvae. Other abbreviations defined in the text.

them daily until all larvae had either developed or died. I exposed one group to $25^{\circ} \mathrm{C}$, the other to $15^{\circ} \mathrm{C}$. I made further estimates of $P_{50}$ and DAP among the small pale larvae by exposing small pale larvae caught from George Pond to continuous long days with food at $15^{\circ}$ and $25^{\circ} \mathrm{C}$. The results in Table 4 show that although temperature had a profound effect on $P_{50}$ and DAP, the $\mathrm{Q}_{10}$ 's for these two parameters were strikingly similar among the wild mix, large yellow, and small pale larvae.

The above experiments were aimed primarily at finding differences between morphs. To investigate differences between stages of development, I examined $T_{50}, \mathrm{PDM}, P_{50}$, and DAP for large yellow larvae from George Pond at $25^{\circ}, 20^{\circ}$, and $15^{\circ} \mathrm{C}$. I determined $P_{50}$ and DAP at $25^{\circ}, 20^{\circ}$, and $15^{\circ} \mathrm{C}$ by exposing 450 larvae (three replicates of 50 larvae at each temperature) to long days with food until all larvae had either developed or died. I determined $T_{50}$ by exposing 150 larvae (three replicates of 50 larvae for each exposure) at $25^{\circ} \mathrm{C}$ to $1,2,3,4$, or 5 long days with food; at $20^{\circ} \mathrm{C}$ to $2,3,4,5$, or 6 long days with food; and, at $15^{\circ} \mathrm{C}$ to $3,4,5$, 6 , or 7 long days with food. After each of these experimental periods, I observed the larvae for 10 additional days, exposed only to short days at $25^{\circ} \mathrm{C}$ without food, after which I scored development and terminated the experiment. I used all 15 points at each temperature at find the least squares regression line and solve for $T_{50}$ at that temperature; to estimate PDM, I subtracted $T_{50}$ from each $P_{50}$ determined at the same temperature.

$T_{50}, \mathrm{PDM}, P_{50}$, and DAP for each temperature are given in Table 5. I used $T_{50}$, PDM, and DAP at $25^{\circ}$ and $20^{\circ} \mathrm{C}$ to calculate the constants $a$ and $b$ in equations (2-4), resulting in nine models, three for each developmental stage. I then calculated $T_{50}$, $\mathrm{PDM}$, and $\mathrm{DAP}$ at $15^{\circ} \mathrm{C}$ using these models and found which model most accurately predicted the observed values at $15^{\circ} \mathrm{C}$. The relationship between the duration of $T_{50}, \mathrm{PDM}$, or DAP and temperature was best described by equations (2), (3), and (4), respectively:

$$
T_{50}=\frac{81.26}{T-1.11}
$$

$$
\begin{gathered}
\log \mathrm{PDM}=\log 2.8+\frac{25-T}{10} \log 2.5 \\
\log \mathrm{DAP}=3.84-2.5 \log T
\end{gathered}
$$

To illustrate the consequences of these temperature relationships, I considered the possible course of development in a fluctuating thermal environment. I recorded the temperature in George Pond on eight dates between March 21, 2 days before the first larva terminated diapause, and May 5, 1969, when the first major emergence of adults occurred. I averaged temperatures taken at $3 \mathrm{~cm}$ and at $1.5 \mathrm{~m}$, the maximum depth of George Pond. I then interpolated for temperatures on dates when no data were taken and rounded off to the nearest whole degree. As seen in Fig. 5, the "pond" temperature profile exhibited a general warming trend, with transient reversals. If the duration of a developmental stage, $D$, at temperature $T$ is $D_{T}$, then percent completion of $D$ at time $t$ (in days), $C_{t}$, is given by

$$
C_{t}=C_{(t-1)}+\frac{100}{D_{T}} \text {. }
$$

Using the temperature relations in equations (5-7), I calculated $C_{t}$ for larvae that commenced the termination of diapause on days 0,10 , and 20 in Fig. 5.

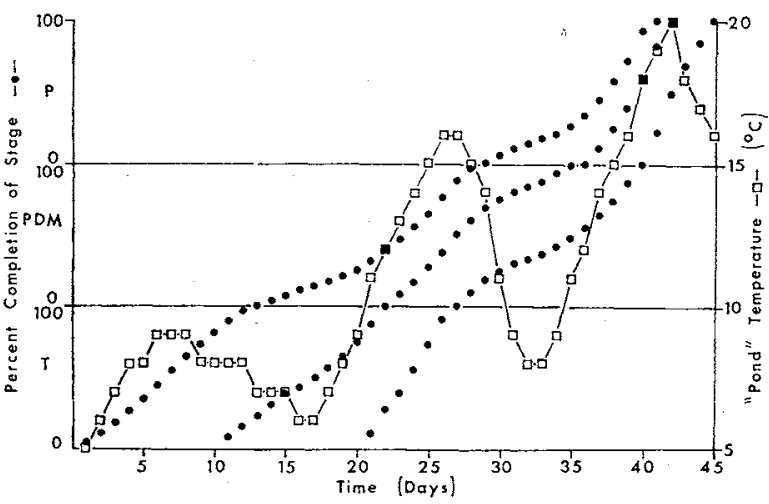

FIG. 5. Model for development of large yellow larvae in a fluctuating thermal environment. Temperature profile calculated as described in the text; relationship between development and temperature as given in equations (5-8). $\mathrm{T}$, termination of diapause; PDM, postdiapause morphogenesis; $\mathrm{P}$, pupal stage. 

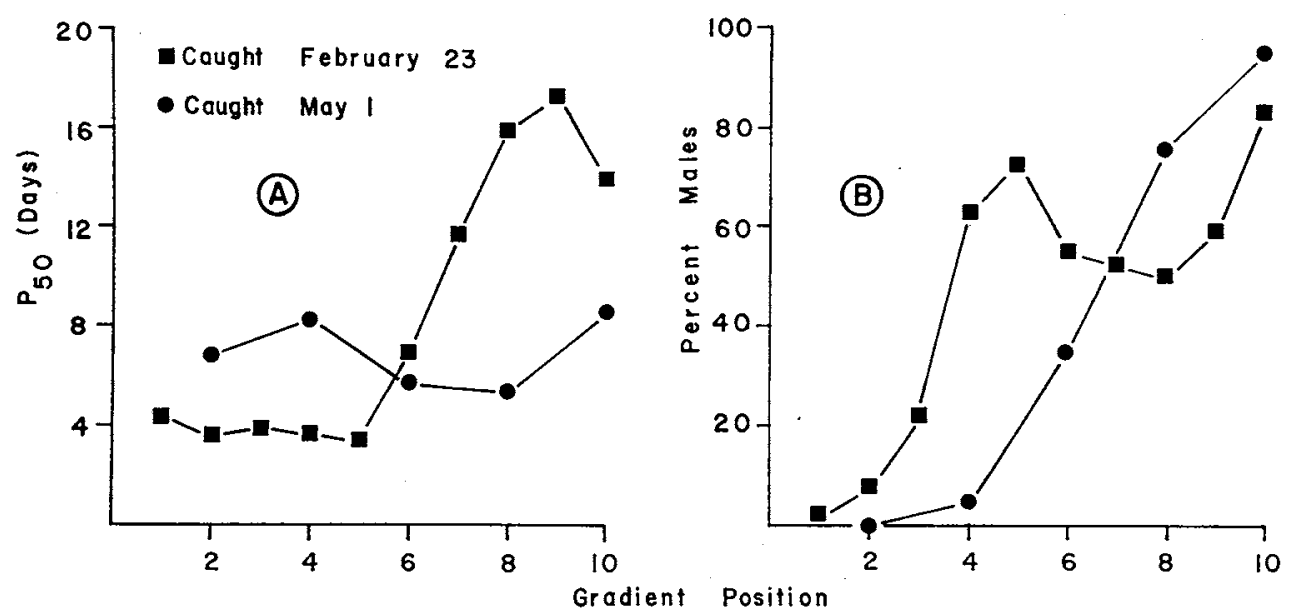

FIG. 6. Distribution of (A) response time to long days with food and (B) sexes among samples caught before and after a major emergence of adults from George Pond in 1970. $P_{50}$ defined in the text.

The progression of development shows that although vernal development was initiated over a 20-day period, the resulting adults emerged over only a 4-day period.

\section{Change in response times in the field}

The above experiments show that $C$. americanus achieves synchrony of adult emergence during widely fluctuating vernal temperatures. It may then be asked whether differences in response time between the large yellow and small pale larvae observed in the laboratory have any reality in nature. The following experiments are designed to illustrate the differences in response time among a wild-caught sample before and after the fast-responding morph has developed.

The first sample was caught through the winter ice of George Pond on February 23, 1970; 500 larvae, graduated from large yellow to small pale in 10 steps of 50 larvae each, were exposed to long days with food on March 3, 1970. The second sample was caught in George Pond on May 1, 1970. At this time a major.emergence of adults had already taken place; the first and second instars of the first summer generation were present in the pond. Very few third instar larvae were observed. Small pale fourth instar larvae were present and presumably represented the slower responding morph of the overwintering generation. On May 5, 1970, 115 of these larvae, graduated from large yellow to small pale in 5 steps of 23 larvae each, were exposed to long days with food.

In both samples, $88 \%-100 \%$ of the larvae in each step of the gradient pupated within 25 days. The distributions of responses within the gradient of both the winter- and spring-captured samples are shown in Fig. 6A. Among the winter-caught larvae, $P_{50}$ was lowest at the large yellow end of the gradient and commenced increasing at GP 7 , reaching a maximum at GP 9. Among the spring-caught larvae, there was no clear correlation between $P_{50}$ and gradient position. The $P_{50}$ 's of the spring-caught larvae were greater than those of winter-caught large yellow larvae and less than those of winter-caught small pale larvae. The sexes were bimodally distributed in the winter-caught sample, with males predominating at GP 5 and GP 10 (Fig. 6B). Among the spring-caught larvae, there was only one peak in the frequency of males, at GP 10. These results show that two physiological morphs are present in the pond during the winter, but after an initial emergence of adults from the pond, only one morph remains.

\section{Discussion}

\section{Sexual and developmental polymorphism}

Variation in the vernal emergence times of adult insects has been noted in the silkmoth, Hyalophora cecropia, and in Chaoborus crystallinus. For 3 separate years, Sternberg and Waldbauer (1969) observed that an average of $7 \%$ of the emerging adult Cecropia preceded the bulk of the population by about 3 weeks. Likewise, Hirvenoja (1960) reported that the emergence times of overwintering C. crystallinus were distributed over a long period. $\mathrm{He}$ attributed the variation in emergences either to different times of oviposition the previous fall or to different "biotypes." Hirvenoja (1960) neither elaborated upon the latter concept, considered diapause, nor undertook any experimental manipulation of these animals. Morris (1971) studied variation in vernal emergence of univoltine fall webworms, Hyphantria cunea. This species is not photoperiodic for the termination of diapause but relies upon ac- 
cumulated chilling. Consequently, the termination of diapause and post-diapause morphogenesis are not readily distinguishable and the day-degrees required for both processes are lumped together and designated as $K_{p}$ (Morris and Fulton 1970). After long, warm summers, $\mathbf{K}_{p}$ increases among overwintering $H$. cunea; after a short, cool summer, the average $\mathrm{K}_{\mathrm{p}}$ declines. Warm summers apparently select against low $\mathbf{K}_{\mathrm{p}}$ individuals since their progeny pupate while it is still warm and consume vital fat reserves before winter; conversely, cool summers select against high $\mathbf{K}_{\mathrm{p}}$ individuals since their progeny cannot complete the larval stages and enter diapause prior to winter. $\mathrm{K}_{\mathrm{p}}$ in $H$. cunea is $\log _{\mathrm{e}}$-normally distributed (Morris and Fulton 1970) so that there is a continuous cline in physiological as well as morphological phenotypes. Variation in $\mathrm{K}_{\mathrm{p}}$ thus reflects variation in the mean response of an entire population rather than changes in the frequency or mean response of discrete phenotypes.

In the case of $C$. americanus, response to long days with food is bimodally distributed (Fig. 1, 2A). The initial peak in development of wild mix larvae is due to the presence of the large yellow morph in the population. The later peak or skewed portion in the distribution of pupation is due to the presence of the small pale morph in the population. I therefore conclude that the size-pigment phenotypes are closely linked to the response-time phenotypes and will interchange these terminologies freely. The basis of this polymorphism might stem from a simple sexual dimorphism or from some variation in developmental response common to both males and females.

A proportion of males greater than $50 \%$ has previously been observed in the overwintering larvae of both culicine (McCrary and Jenner 1965) and chaoborine (Hirvenoja 1960) mosquitoes, so the imbalance found in the current study (Table 1) is not unusual. In light of the observation (Fig. 2B) that female larvae take longer to develop than do male larvae, it is striking that the females predominate in the faster responding morph and males in the slower responding morph. Furthermore, males and females are quite evenly distributed in a wild mix population (Fig. 2C). Herein lies a paradox: males respond faster than females but comprise less of the fastest developing portion of the population. To resolve the inconsistency, I propose the following:

(1) Size and pigmentation are markers, but in themselves are not causative of the developmental rate.

(2) Two developmental morphs do indeed exist, the faster being larger and yellower, the slower being smaller and paler.

(3) Within each morph, however, the females are larger and yellower than the males.
The 1969 wild mix population, showing a distinct bimodal distribution of development (Fig. 1, 2A), provided a good opportunity to test these assumptions. Consequently, I undertook the gradient experiment. If the above proposals are valid, both males and females should show a bimodal distribution, one peak each in a faster and slower developing portion of the population, i.e., at the largeryellower and the smaller-paler ends of the gradient, respectively. Furthermore, the male peaks should be staggered toward the small pale end with respect to the female peaks. The gradient exhibited precisely these characteristics (Fig. 2D).

\section{Homeostasis}

Water temperatures in shallow bodies of water such as George Pond may be highly variable during the course of a temperate spring. While the overall trend is from cold to warm, transient reversals can occur and the pond may even refreeze after a long period of warming. The response of individual $C$. americanus larvae to various temperatures (Fig. 5) may be interpreted as a developmental homeostasis promoting synchronous adult emergence in favorable weather.

Because of the relationships between successive stages of development and temperature (equations 5-7), synchronous adult emergence is achieved through the action of and not despite fluctuating vernal temperatures (Fig. 5). While day 45 in Fig. 5 corresponds to May 5, the date of first major emergence of adults from George Pond in 1969, the coincidence of emergence in nature with that predicted by the model may be fortuitous. I took only eight measurements of temperature during this 45-day period and there is no assurance that they represent the true effective temperatures in nature. Nonetheless, the profile of pond temperature relates to reasonable temperatures in George Pond. The model of development in C. americanus illustrated in Fig. 5 is therefore probably a realistic approximation of events taking place in nature.

The ability of large yellow $C$. americanus to achieve synchronous emergence through variation in environmental temperature does not mean that the large yellow and small pale morphs commingle their development. As shown by the bimodal distribution of males (Fig. 6B), two morphs are present in the overwintering population. After an initial emergence of adults in the spring, only one morph remains, as shown by the unimodal distribution of males (Fig. $6 \mathrm{~B}$ ). The $P_{50}$ 's of the remaining morph are uniformly higher than those of the large yellow larvae in the overwintering population, indicating that they belong to the slow-responding morph. The $P_{50}$ 's of the larvae caught May 1 range from 5.6 to 9.5 days. Many of them have probably terminated diapause 
and are completing post-diapause morphogenesis, which for small pale larvae requires 5.4-7.8 days at $25^{\circ} \mathrm{C}$ (Table 3 ).

A second consequence of the temperature relationships illustrated in Fig. 5 is that the closer an overwintering $C$. americanus comes to facing an aerial existence, the more its advance toward that confrontation is retarded by a small drop in temperature. Each stage in the process of diapause termination and adult development may be seen as passing through zones that progressively protect the animal from emergence on an unfavorably cold day. Aerial temperature is highly variable, especially in early spring; it can drop below freezing (presumably lethal to adult chaoborids) in a few hours. Water temperature, even in a small pond, is much less variable, but it does change. One night of freezing aerial temperature is of little consequence to a larva in the midst of diapause termination because the animal is aquatic. The larva therefore continues responding to the photoperiodic and trophic cues with long-term reliability, and a small drop in the surrounding water little affects progress towards eclosion. If, however, the overwintering animal is approaching the end of the pupal stage, the particular aerial temperature on that particular night or sequence of nights is extremely important; hence, it is more protected from this hostile world if it makes a large developmental adjustment in response to a small temperature drop in the surrounding medium.

\section{Significance of polymorphism in C. americanus}

To some extent, individual $C$. americanus larvae contend with uncertain vernal climate through homeostatic adjustment of development. Some springs are, however, especially severe: a long warm period during which long-day photoperiod and abundant food are available can be interrupted by a cold period during which the pond freezes over. This sequence of events occurred in the spring of 1967. Prior to this cold period, a substantial proportion of the overwintering population had pupated. During the cold spell, I observed no eclosion of adults; afterwards, only a few pupae were left in the pond. I presumed that the cold eliminated pupated individuals either (1) by killing them directly as they were no longer protected by any metabolic tolerances with which diapause may previously have endowed them or (2) by exposing them to increased predation. The second point is not as trivial as it might at first seem. As the pupae mature, the adult cuticle is formed. The darkness of this cuticle is dependent upon the temperature during development and becomes almost black at temperatures below $15^{\circ} \mathrm{C}$. This dark coloration may then render the developing organisms more visible and therefore more susceptible to pre- dation than those developing under warmer conditions. It would therefore appear that each individual does not have the capacity to survive and reproduce in the total array of spring climates that occur at George Pond. Selection and adaptation in a changing environment may have produced a polymorphic population where each extreme morph most advantageously exploits opposite vernal extremes.

A rapid reponse time to photoperiodic and trophic cues would be most advantageous in years characterized by early springs that become continuously warmer. A conservative response time would be appropriate in a year during which an initial thaw and plankton bloom is followed by refreezing of the pond. Both of these conditions, as well as intermediate ones, occur at George Pond. Fortuitously, they occurred in the appropriate sequence and I was able to observe changes in response time of $C$. americanus after two extremes of vernal climate. It is important to note that $P_{50}$ declines with prolonged chilling, either in nature or in the laboratory (Bradshaw 1972), so interannual comparisons must take into account both date of capture and duration of laboratory storage.

As mentioned, the spring of 1967 was characterized by a warm period followed by refreezing of the pond. During the following spring, 1968, the thaw occurred earlier and the temperature became continuously warmer. If the observed polymorphism is genetically mediated, the frequencies of genes responsible for the faster responding phenotype should have declined in 1967. The $P_{50}$ 's of the population overwintering 1967-1968 would then increase over the $P_{50}$ 's of the previous winter. Likewise, after the warm 1968 spring, the frequencies of genes responsible for the faster responding phenotype should have increased, showing a consequent decline in $P_{50}$ 's during the winter of 1968-1969. The $P_{50}$ 's listed in Table 1, and the distributions shown in Fig. 1 support this proposition. Furthermore, the observation that both the large yellow and the small pale larvae tend to respond faster in years when the wild mix is responding more rapidly than they do in years when the wild mix is responding more slowly suggests polygenic control of the response to food and photoperiod.

Response to sub-maximal stimuli is greatest during years or at a time of year when $P_{50}$ is lowest (Table 4 ), suggesting that factors selecting for faster termination of diapause also select for response to long days alone or, to a lesser extent, food alone. Rate of response to long days with food by an overwintering population increases after a previous spring that was early, warm, and continuous. These springs may be termed predictable since the initial thaw accompanied by long days with food is a reliable indicator of future mild conditions. Following un- 
predictable springs when the pond refreezes after a portion of the overwintering population has initiated development and pupated, rate of response to long days with food declines. Unpredictable springs thus maintain the rigid requirement of simultaneous long days with food for termination of diapause; predictable springs promote relaxation of reliance upon coincident photoperiodic and trophic cues.

Among the large yellow larvae, $P_{50}$ in 1967-1971 ranged from 3.7 to 8.5 days (Table 2) while $P_{50}$ among the small pale larvae ranged from 13.8 to 27.5 days in $1968-1970$ (Fig. 1A, Fig. 4). $P_{50}$ for the fast-responding morph was longest in 1968 (8.5 days) but did not approach the shortest $P_{50}$ for the slow-responding morph, 13.8 days in 1969. The fast- and slow-responding phenotypes, although somewhat modifiable, are therefore limited with respect to their variability. Part of this variation involves the expression of phenotypes responding to submaximal stimuli. Genes responsible for promoting development under conditions of long days alone or food alone are apparently masked by those governing response time. Among the slow-responding morph, the hypostasis is obligatory. Among the fast-responding morph, hypostasis is facultative, and a succession of predictable springs unmasks the ability to utilize a single cue for the resumption of development.

The size of the head capsules and trophic apparatus indicate that the small pale and large yellow larvae are both in the terminal (fourth) larval instar. This conclusion is supported by the observation that small pale larvae do not undergo a larval molt prior to pupation. The results in Fig. 4 bear on the question of whether the small pale individuals are younger fourth instar larvae than the large yellow individuals. Short days with food followed by long days with or without food (Fig. 4B) resulted in slower development than would be expected from response to these stimuli without prior treatment (Fig. 4A). This retarded development could be similar to that in the wheat stem sawfly, Cephus cinctus, where diapause is normally terminated by chilling but exposure to $35^{\circ} \mathrm{C}$ can reverse the effects of prior chilling (Salt 1947, Church 1955). In C. americanus, chilling promotes rapid response to long days with food (Bradshaw 1969); the inability of long days with food to elicit more rapid development among larvae not responding promptly to short days with food could then be due to partial reversal of chilling by 25 days of warm temperature.

Regardless of the retardation effects of warming, subsequent response to long days with food among small pale larvae in GP 7-10 is slower than among large yellow larvae in GP 1-6 (Fig. 3B). Furthermore, 25 days of feeding did not endow larvae in GP 7-10 with the ability to respond to long days alone. At the same time, this ability, although re- tarded, was preserved among larvae in GP 1-6. These results show that short days with food do not tranform slow- into fast-responding phenotypes, either quantitatively or qualitatively. The developmental basis of response-time polymorphism is then related to temporal differences in the termination of diapause and post-diapause morphogenesis (Table 3). Both $T_{50}$ and PDM require more time at higher gradient positions, but the increase in PDM with gradient position is both absolutely and proportionally less than that of $T_{50}$. Adaptation to uncertain vernal environments has therefore relied more upon modification of switch mechanisms already connected to environmental cues than it has upon tampering with the normal ontogenetic program.

Whether there is a heterotic effect in the balancing of this response-time polymorphism in C. americanus is unknown and untestable in this investigation. The polymorphism could be stabilized by the fact that the alternate environments, from the point of view of the population, occur frequently, and in a random fashion. The environment which $C$. americanus encounters is thus coarse grained or "patchy" (Levins and MacArthur 1966) with respect to the optimum time to terminate diapause, rather than fine grained or continuous. The important claim here is that the time they should take to initiate development must be considered a dimension of the niche. If the environmental variability in the optimum time to initiate development is large, the opportunity for a population containing many phenotypes is greater than might otherwise be possible. If one considers each spring as a different patch of the same niche, George Pond, then one can visualize an extremely broad niche which in itself serves to maintain phenotypic variability (Haldane and Jayakar 1963, Van Valen 1965, Levins and MacArthur 1966, Powell 1971, Roughgarden 1972).

This variability, as these authors pointed out, may permit maintenance of a larger population than would be found if only one morph were present. Chaoborus americanus is certainly abundant in George Pond. I have captured overwintering larvae with a dipnet through a hole in the ice at a rate of $5 \mathrm{~kg}$ per hour. The specific developmental polymorphism that I propose for $C$. americanus may explain in part its ability to capitalize upon the opportunities available in a food-rich, predator-lean, but shallow and therefore highly variable body of water, such as George Pond.

\section{Persistence of polymorphism}

Polymorphism in a population may cease to exist for two diametrically opposed reasons. First, fluctuating selection pressures may effect the fixation of one of the morphs. Second, polymorphism may cease to exist as the result of just those factors which 
TABLE 6. General model for persistent and non-persistent stable polymorphism in face of selective pressure to evolve into a monomorphic, homeostatic population

I. Stable polymorphism evolving into individual homeostasis
A. Developmental option precedes selective force
B. Cue precedes selective force
C. Cue available at or before time of develop- mental option

II. Stable polymorphism not evolving into individual homeostasis
A. Developmental option precedes selective force
B. Cue present before, at time of, or after selec- tive force
C. Cue unavailable at time of developmental option

$I^{\prime}$. Initiation of diapause in C. americanus (Bradshaw 1972)

$A^{\prime}$. Option to diapause or develop precedes winter

$B^{\prime}$. Short daylength precedes winter

$C^{\prime}$. Short days present at time larva is in appropriate instar

II'. Termination of diapause in $C$. americanus

$A^{\prime}$. Option to initiate or delay development precedes refreezing of pond

B'. Cue same as selective force, i.e., refreezing of pond

$C^{\prime}$. Whether or not pond will refreeze unknown at first thaw and bloom combine to stabilize it, i.e., heterosis and environmental variability. If two functionally related alleles are present for a long time, selection would favor duplication, recombination, and inversion, causing the two former alleles to lie in a close linkage group. Assuming independent operators, each of these former alleles or groups of alleles would have its previous capacity and could respond separately to the particular environmental factors favoring expression of alternate phenotypes. Individuals incorporating such an arrangement would possess the same phenotypic potential of an entire population that was polymorphic at that locus. Selection would then result in a monomorphic population of homeostatic individuals.

If it is precisely those factors which stabilize polymorphism that also promote its evolution into individual homeostasis, then one could visualize polymorphism as a purely transient state. A clue to what maintains polymorphism in a population comes from an analysis of diapause in Chaoborus americanus. During the year, individuals reaching the terminal larval instar are faced with a developmental optionto diapause or continue development. Long days are an excellent indication that conditions favorable for development are going to continue; short days reliably herald the encroaching winter. A homeostatic individual thus has every advantage: it can develop when it encounters long days as a larva and diapause when it encounters short days as a larva. The important point is that the environmental cue (day length) is present at or before the time of developmental option (diapause:no-diapause), and both are present before the environmental selective force (winter).

An inspection of the spring cues reveals a rather different case for the termination of diapause in $C$. americanus. When the pond thaws in late March and there is a plankton bloom, both sufficient day length and food are present for development to be initiated. What is not present is an environmental cue that will predict whether or not the pond is going to refreeze. Yet, at the time of the initial thaw, the individual has the developmental option to continue diapause or to reinitiate development. Since there is no cue as to the prudent course, a homeostatic individual has no advantage over any other individual; greatest fitness will accrue to those individuals that are pre-adapted for that particular spring climate.

This scheme has been summarized in Table 6 . Basically, the model predicts that the evolution of individual homeostasis or pre-acclimation is favored when the environmental cue is available at or before the time of developmental option and when both these events precede the environmental selective force. Otherwise, if the cue occurs after the time of developmental option, whether or not it occurs before, at the time of, or after the selective force, selection will favor different adaptive phenotypes residing in separate individuals of the population, i.e., polymorphism.

\section{ACKNOWLEDGMENTS}

I thank Alan Feduccia, Douglas Futuyma, and Christina Holzapfel for many hours of enjoyable and critical discussion; Douglas Futuyma, Nelson Hairston, Christina Holzapfel, Jonathan Roughgarden, David Shappirio, and Edward Wilson for reviewing various stages of the manuscript; Francis Evans for permission to use the E. S. George Reserve; and, the National Institutes of Health for support through Grants GM06101, 2T1GM989, and 2F02GM41926.

\section{Literature Cited}

Bradshaw, W. E. 1967. The role of morphological type and food in the termination of larval diapause in Chaoborus (Diptera, Culicidae). Am. Zool. 7: 728 . 1969. Major environmental factors inducing the termination of larval diapause in Chaoborus americanus Johannsen (Diptera: Culicidae). Biol. Bull. 136: $2-8$.

1970. Interaction of food and photoperiod in the termination of larval diapause in Chaoborus americanus (Diptera: Culicidae). Biol. Bull. 139: 476484.

. 1972. Photoperiodic control in the initiation of diapause by Chaoborus americanus (Diptera: Culicidae). Ann. Entomol. Soc. Am. 65: 755-756. 
Bradshaw, W. E., and L. P. Lounibos. 1972. Photoperiodic control of development in the pitcher-plant mosquito, Wyeomyia smithii. Can. J. Zool. 50: 713719.

Church, N. S. 1955. Hormones and the termination and reinduction of diapause in Cephus cinctus Nort. (Hymenoptera: Cephidae). Can. J. Zool. 33: 339369.

Cook, E. F. 1956. The Nearctic Chaoborinae (Diptera: Culicidae). Bull. Minn. Agr. Exp. Sta. 218: 1-102.

Haldane, J. B. S., and S. D. Jayakar. 1963. Polymorphism due to selection of varying direction. J. Genet. 58: 237-242.

Hirvenoja, M. 1960. Ökologishe studien über die Wasserinsekten in Riihimäki (Südfinnland) I. Chaoborinae (Diptera: Culicidae). Ann. Entomol. Fenn. 26: 3144.

Levins, R., and R. MacArthur. 1966. Maintenance of genetic polymorphism is a spatially heterogeneous environment: variation on a theme by Howard Levene. Am. Nat. 100: 585-590.
McCrary, A. B., and C. E. Jenner. 1965. Influence of daylength on sex ratio in the giant mosquito, Toxorhynchites rutilus, in nature. Am. Zool. 5: 206.

Morris, R. F. 1971. Observed and simulated changes in genetic quality in natural populations of Hyphantria cunea. Can. Entomol. 103: 893-906.

Morris, R. F., and W. C. Fulton. 1970. Heritability of diapause intensity in Hyphantria cunea and correlated fitness responses. Can. Entomol. 102: 927-938.

Powell, J. R. 1971. Genetic polymorphism in varied environments. Science 174: 1035-36.

Roughgarden, J. 1972. Evolution of niche width. Am. Nat. 106: 683-718.

Salt, R. W. 1947. Some effects of temperature on the production and elimination of diapause in the wheat stem sawfly, Cephus cinctus Nort. Can. J. Res. (D) 25: $66-86$.

Sternburg, J. G., and G. P. Waldbauer. 1969. Bimodal emergence of adult Cecropia moths under natural conditions. Ann. Entomol. Soc. Am. 62: 1422-1429.

Van Valen, L. 1965. Morphological variation and width of ecological niche. Am. Nat. 99: 377-390. 